\title{
Diagnóstico diferencial del carcinoma basocelular pigmentado
}

\author{
Flor Liliana Urrego-Rivera ${ }^{a}$ y Cristina Faura-Berrugab . $^{b}$
}

\author{
a M.I.R. de Medicina de Familia. \\ Centro de Salud Zona 3. \\ Albacete (España). \\ ${ }^{\mathrm{b}}$ Departamento de Dermatología \\ y Venereología. \\ Complejo Hospitalario \\ Universitario de Albacete. \\ Albacete (España). \\ Correspondencia: \\ Flor Liliana Urrego-Rivera \\ Centro de Salud Zona 3. Pza. \\ de La Mancha, s/n. C.P. 02001. \\ Albacete (España). \\ Correo electrónico: \\ liliurri@yahoo.com \\ Recibido el 17 de noviembre de \\ 2014. \\ Aceptado para su publicación el \\ 17 de enero de 2015
}

\begin{abstract}
RESUMEN
El carcinoma basocelular es el tipo más común de cáncer cutáneo y la neoplasia más frecuente en el ser humano. Este tumor maligno es localmente infiltrante, agresivo y destructivo, pero su capacidad para metastatizar es muy limitada. Existen diferentes tipos: nodular, ulcerativo, pigmentado, esclerosante y superficial. Presentamos el caso de un paciente con carcinoma basocelular pigmentado en el que fue necesario hacer un diagnóstico diferencial con otras patologías como el melanoma maligno, el nevus azul y la queratosis seborreica, en las cuales el manejo y pronóstico del paciente son diferentes.
\end{abstract}

Palabras Clave: Carcinoma Basocelular Pigmentado. Queratosis Seborreica. Melanoma Maligno. Nevus.

\section{ABSTRACT \\ Differential diagnosis of pigmented basal cell carcinoma}

Basal cell carcinoma (BCC) is the most common cutaneous cancer in humans. BCC is locally invasive, aggressive, and destructive but slow in growing, and there is very limited (literally no) tendency to metastasize. Clinically, there are different types: nodular, ulcerating, pigmented, sclerosing, and superficial. We report a pigmented basal cell carcinoma case, which required differential diagnosis from other pathologies such as superficial melanoma, seborrheic keratosis and blue nevus, in which management and prognosis are different.

Key words: Basal Cell Carcinoma, pigmented. Keratosis, Seborrheic . Malignant Melanoma. Nevus.

\section{INTRODUCCIÓN}

Los problemas dermatológicos son frecuentes en Atención Primaria y se estiman en un $10 \%$. Por su importancia destacan los tumores dermatológicos $y$, entre ellos, el carcinoma basocelular, que es el tumor más frecuente en la piel ${ }^{1}$. El carcinoma basocelular es una neoplasia epitelial de malignidad limitada por un crecimiento lento y excepcional capacidad para dar metástasis a distancia. Se origina a partir de células indiferenciadas y pluripotentes de la capa basal epidémica. En su origen intervienen factores extrínsecos (factores medioambientales como la fotoexposición) e intrínsecos (genéticos o factores del huésped como la inmunodepresión). La radiación ultravioleta acumulada juega un papel etiopatogénico fundamental ${ }^{2}$. El diagnóstico es clínico, pero se confirma mediante la histología por biopsia. Su diagnóstico diferencial es amplio debido a la variedad de sus formas clínicas y se plantea principalmente con las siguientes entidades: queratosis actínica, queratosis seborreica, tumores en anejos, nevus melanocítico, melanoma, enfermedad de Bowen y carcinoma epidermoide ${ }^{3,4}$. 


\section{OBSERVACIONES CLÍNICAS}

Varón de 65 años con antecedentes personales de hipertensión arterial, diabetes mellitus tipo 2 y dislipemia en tratamiento con atorvastatina $10 \mathrm{mg} / \mathrm{día}$, metformina $850 \mathrm{mg} /$ día y enalapril $5 \mathrm{mg} /$ día. De profesión albañil. Derivado desde nuestra consulta de Atención Primaria al servicio de Dermatología por presentar una lesión en la espalda asintomática de 5 años de evolución con crecimiento progresivo, que el paciente describía como un "lunar" y por eso no había consultado antes. Durante la exploración física se observaba una tumoración de $1 \mathrm{~cm}$ en la región escapular izquierda de coloración azulada negruzca, de consistencia indurada y no adherida a planos profundos (figura 1A). Los diagnósticos diferenciales realizados por el médico de familia, considerando las características y la pigmentación de la lesión, fueron: melanoma, queratosis seborreica y carcinoma basocelular pigmentado. Con estos diagnósticos posibles se derivó a la consulta de Dermatología.

En el servicio de Dermatología se visualizó la lesión con el dermatoscopio, objetivándose telangiectasias arboriformes en la superficie (Figura 1B) ${ }^{5}$. Se plantearon como posibles diagnósticos: carcinoma basocelular pigmentado, melanoma maligno, nevus azul o queratosis seborreica.

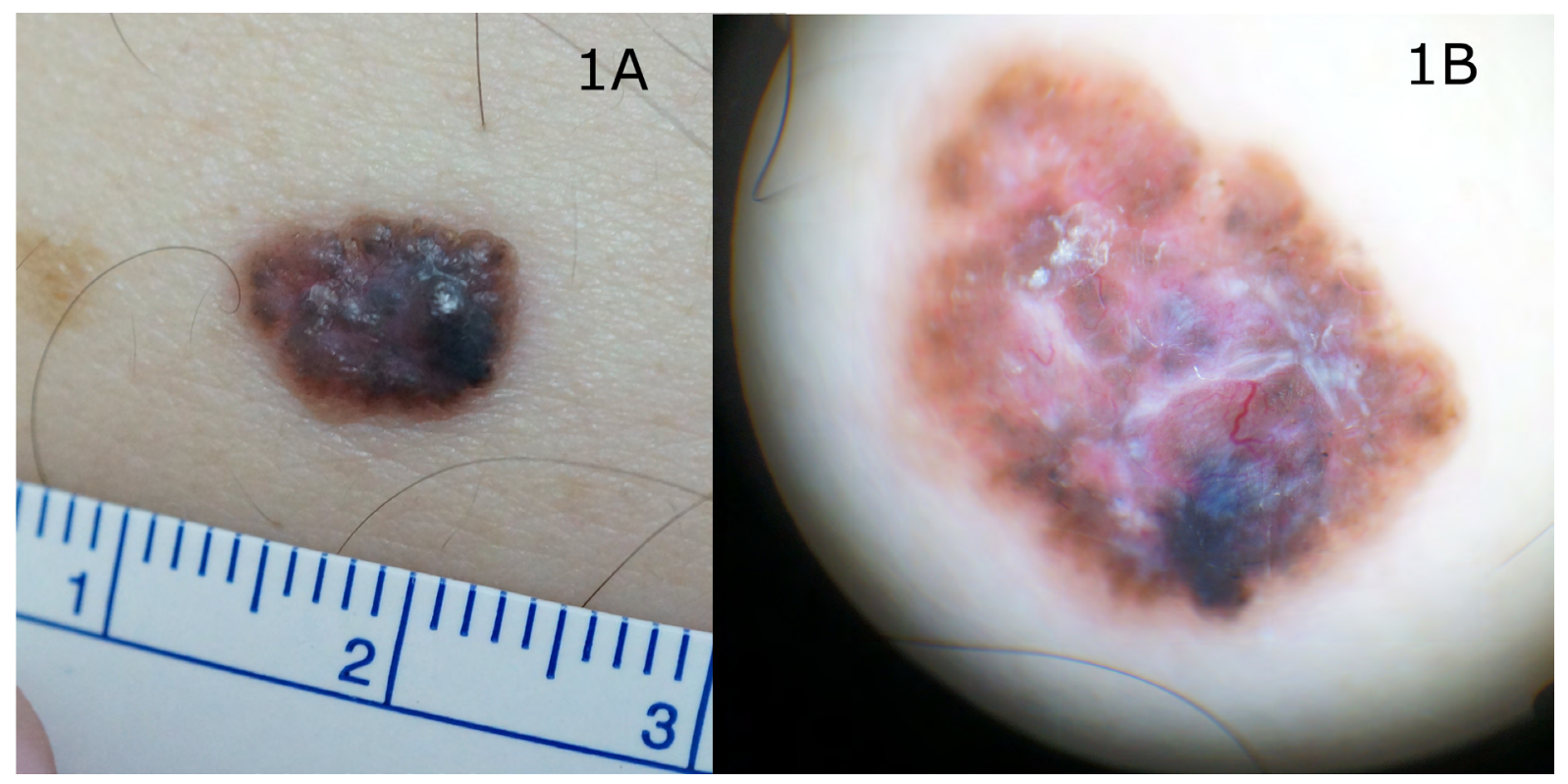

Figura 1. A: Tumoración de $1 \mathrm{~cm}$ en región escapular izquierda, de coloración azulada negruzca, de consistencia indurada y no adherida a planos profundos. B: Visión de la lesión con el dermatoscopio. Se aprecian telangiectasias arboriformes en la superficie.

Se procedió a la extirpación de la lesión. En el informe anatomopatológico de la pieza se halló una proliferación de células basaloides atípicas, agrupadas en disposición en empalizada en la periferia, y acúmulos de melanina en los agregados de las células atípicas, compatible con carcinoma basocelular. El paciente presento una adecuada evolución con posteriores revisiones anuales en el servicio de Dermatología.

\section{DISCUSIÓN}

El carcinoma basocelular (CBC) es el tipo más co- mún de cáncer cutáneo. Este tumor maligno es localmente infiltrante, agresivo y destructivo, pero su capacidad para metastatizar es muy limitada. Es más frecuente en varones y su aparición suele afectar más frecuentemente a mayores de 40 años. Los factores predisponentes son: personas con fototipos cutáneos I y II (según la clasificación de Fitzpatrick los fototipos I y II presentan reacciones fotoalergicas al exponerse al sol), antecedentes personales de una exposición solar intensa y prolongada en la juventud, inmunosupresión y exposición a radiaciones ionizantes. La gran mayoría de los CBC ocurren de forma esporádica, aunque también pueden ser hereditarios (síndrome de Gorlin y en el xeroderma pigmentoso $)^{2,4}$. 


\section{Existen cinco variantes clínicas²:}

- Carcinoma basocelular nodular: se presenta como una pápula o nódulo traslúcido (perlado), del color de la piel o rojizo, superficie lisa con telangiectasias, bien delimitado y de consistencia firme.

- Carcinoma basocelular ulcerado: úlcera a menudo con costras con un borde sobreelevado que también es traslucido, perlado con telangiectasias en su superficie y de consistencia firme.

- Carcinoma basocelular esclerodermiforme: aparece como una pequeña placa de aspecto indurado como si se produjera una cicatriz superficial, a menudo mal delimitada, del color de la piel pero también con una pigmentación como pimienta.

- Carcinoma basocelular multicéntrico superficial: aparece en forma de placas delgadas sin llegar a presentar una tumoración exofítica de una coloración rosada o rojiza. A veces se pueden observar telangiectasias y una leve descamación superficial.

- Carcinoma basocelular pigmentado: puede ser de diversas coloraciones, desde marrón a azul o negro. La superficie es lisa y brillante, de consistencia indurada. El pigmento del tumor se debe a melanina que se acumula tanto en los nidos de células epiteliales basaloides malignas como en la dermis alrededor del tumor (en forma de melanófagos).

En resumen, el diagnóstico del CBC es clínico y se confirma mediante anatomía patológica. El tratamiento de elección es la extirpación radical del tumor y posterior cierre primario, colgajo cutáneo o injerto ${ }^{2-4,6}$.

Nuestro paciente presentaba la variante de carcinoma basocelular pigmentado, cuya peculiaridad de presentación clínica nos hace muy difícil en ocasiones diferenciarlo de otras patologías como el melanoma maligno, un nevus azul o una queratosis seborreica; de ahí la importancia del papel del médico de familia, ya que es el primero en evaluar a estos pacientes, realizar un diagnóstico precoz y derivar para la confirmación de la sospecha diag- nostica.

Dentro del diagnóstico diferencial hemos de hacer las siguientes consideraciones:

- El caso del melanoma maligno (figura 2) es un tumor que se origina de los melanocitos, es actualmente una neoplasia de máxima actualidad por su alarmante incremento. Los factores de riesgo principales para el desarrollo de un melanoma son: un número elevado de nevus, la presencia de nevus atípicos o displásicos, fototipos I y II, quemaduras solares en la infancia, antecedente de melanoma familiar y enfermedades previas que inmunodepriman al paciente. El diagnóstico es clínico y se basa en la regla $A B C D E$ (Asimetría, Bordes, Color, Diámetro y Evolución). La cirugía es el tratamiento de elección, con la realización además de ganglio centinela en función del grosor en milímetros de la profundidad del tumor?

- El nevus azul (figura 3) es una proliferación localizada de melanocitos dérmicos productores de melanina. Suele ser adquirido y de comportamiento benigno. Clínicamente se presenta como una pápula o nódulo de bordes bien definidos y color entre azul oscuro, gris y negro. Por lo general se localizan a nivel de dorso de manos y pies. En cuanto al diagnóstico, suele ser clínico, y únicamente se extirpan aquellos que hayan presentado algún cambio o sean de aparición reciente (diagnóstico diferencial con CBC pigmentado y melanoma maligno nodu$(\operatorname{ar})^{2}$.

- La queratosis seborreica (figura 4) es el tumor epitelial benigno más frecuente en el ser humano. Está constituida por una proliferación de queratinocitos monomorfos sin atipias, con papilomatosis marcada. La queratosis seborreica forma parte del proceso fisiológico del envejecimiento cutáneo. No requiere tratamiento ya que no degenera en lesiones malignas. El diagnóstico suele ser clínico².

Concluimos que el carcinoma basocelular pigmentado es una de las variantes de presentación clínica del carcinoma basocelular en el que el diagnóstico diferencial es de vital importancia, ya que de ello dependerá el tratamiento y el pronóstico de nuestros pacientes. 


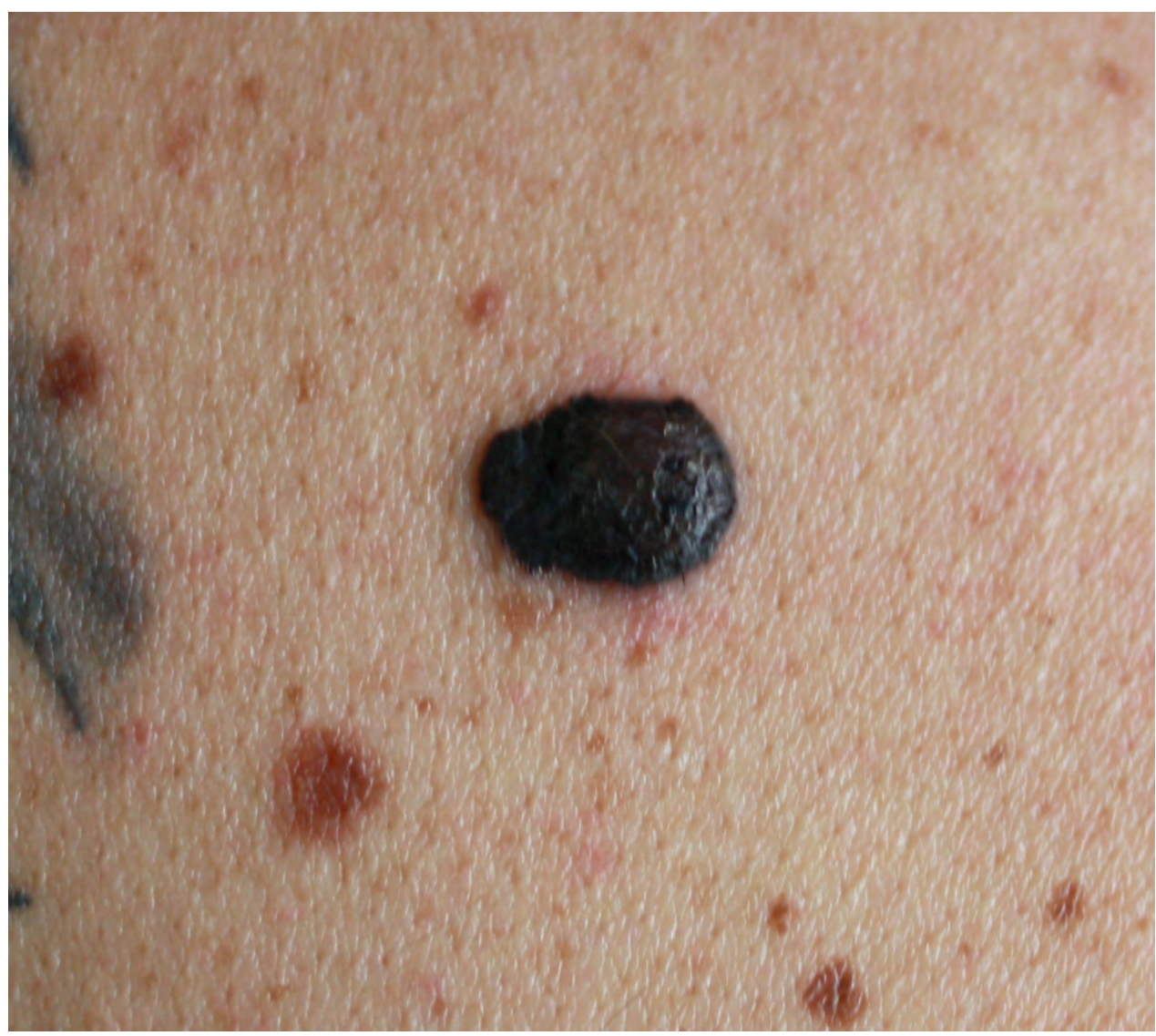

Figura 2. Melanoma maligno

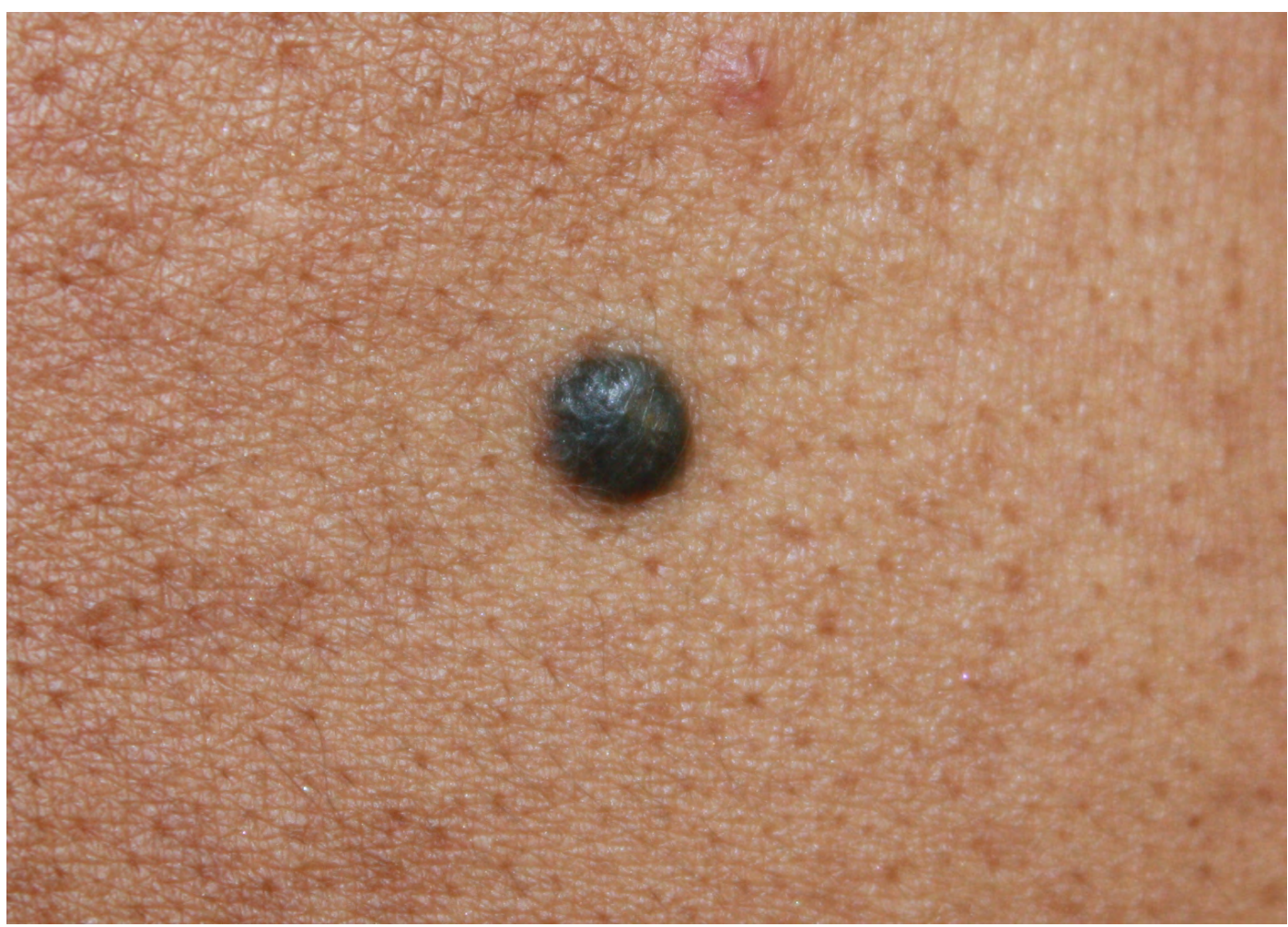

Figura 3. Nevus azul 


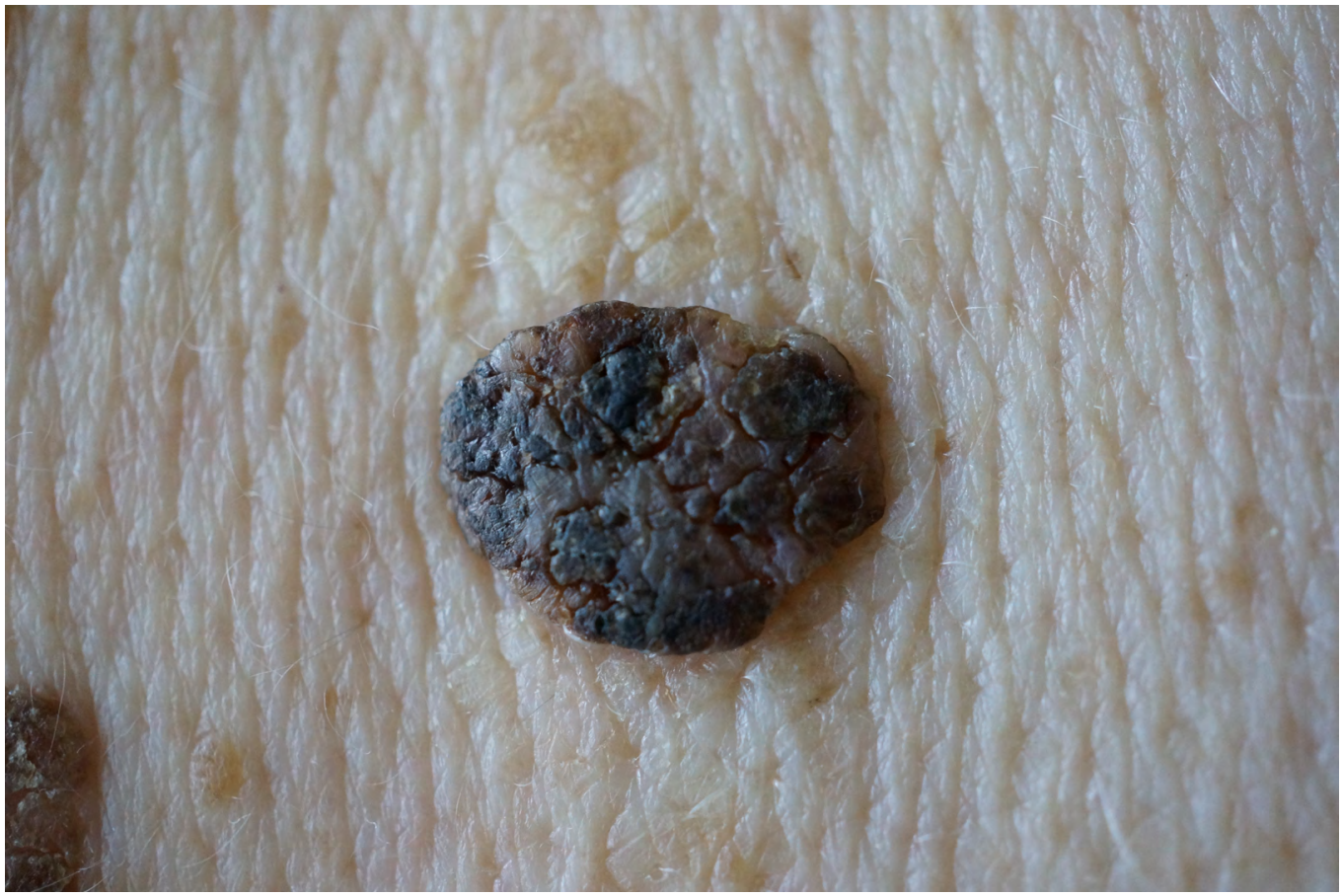

Figura 4. Queratosis seborreica

\section{BIBLIOGRAFÍA}

1. Rodríguez Caravaca G, García-Cruces Méndez J, Hobson S, Rodríguez Caravaca F, Villar del Campo M, González Mosquera M. Validez del diagnóstico clínico del carcinoma basocelular en atención primaria. Aten Primaria. 2001; 28 (6): 391-5.

2. Wolff K, Goldsmith L, Katz S, Gilchrest B, Paller A, Leffell D, edits. Fitzpatrick's Dermatology in General Medicine Color. 7th Edition. New York: McGraw-Hill; 2008.

3. Fisterra.com, Atención Primaria en la Red [sede Web]. La Coruña: Fisterra.com; 1990- (actualizada el 4 de Marzo
2013; acceso el 11 de Enero 2015). Disponible en: http:// www.fisterra.com

4. Rubin Al, Chen EH, Ratner D. Basal-cell carcinoma. N Engl J Med. 2005; 353 (21): 2262-9.

5. Lallas A, Apalla Z, Argenziano G, Longo C, Moscarella E, Specchio $\mathrm{F}$ et al. The dermatoscopic universe of basal cell carcinoma. Dermatol Pract Concept. 2014; 4 (3): 11-24.

6. Telfer NR, Colver GB, Morton CA; British Association of Dermatologists. Guidelines for the management of basal cell carcinoma. Br J Dermatol. 2008; 159 (1): 35-48.

7. García Rodríguez M. Melanoma. Clínica y tratamiento. Medicine. 2009;10(27): 1817-29. 